\title{
AGENCIAMENTOS ECOLÓGICOS: ENTRE MÁQUINAS TÉCNICAS E MÁQUINAS DESEJANTES
}

Adalberto Ferdnando Inocêncio ${ }^{1}$

Resumo: Buscou-se, neste artigo, colocar em evidência quais máquinas ou agenciamentos maquínicos estão em jogo na experimentação de modos ecológicos de vida. A hipótese de investigação foi a de que os modos de se relacionar com o meio ambiente se diferem conforme os agenciamentos maquínicos que Ihes são imanentes. Nas seções analíticas, analisam-se um purificador de água portátil da marca LifeStraw e a projeção do nascer do sol em uma tela de Led, em Beijing, como exemplos de máquinas técnicas; e duas obras dos artistas brasileiros Roberta Carvalho e Eduardo Srur, como exemplos de máquinas desejantes. Em cada um desses casos, buscou-se demonstrar que tipo de subjetividade é imanente aos respectivos agenciamentos maquínicos analisados.

Palavras-chave: Agenciamento Maquínico; Subjetivação; Modos de Vida.

Abstract: The aim, in this article, was to emphasize which machines or machinist agencyings are on the line in experimentation of ecological ways of life. The investigation hypothesis was that the ways of relating to the environment are different according to the machinist agencyings that are inherent to them. In the analytical sections, it's being analyzed a portable water purifier from the LifeStraw brand and the projection of the sunrise on a Led screen, in Beijing, as examples of technical machines; and two pieces from Brazilian artists Roberta Carvalho and Eduardo Srur, as examples of desiring machines. In each of these cases, it was persued to demonstrate what type of subjectivity is inherent to the respective analyzed machinist agencying.

Keywords: Machinist Agencying; Subjectivation; Lifestyle.

1 Universidade Estadual de Maringá (UEM). E-mail: afinocencio88@gmail.com. Link para o Lattes: http://lattes.cnpq.br/2512088867369823.

Revbea, São Paulo, V. 16, № 6: 10-30, 2021. 


\section{Introdução}

O presente artigo resulta de uma tese de doutoramento que pretendeu investigar de quais maneiras a proliferação discursiva da crise ambiental, que emergiu nas últimas décadas, se relaciona com a construção das subjetividades no tempo presente. Admitindo que, frente a esta crise, a vida tanto é capturada como se prolifera em movimentos intensivos de recusa dos agenciamentos metamodalizados (que incorrem sempre na repetição) estabelecidos, o objetivo central desta investigação foi o de colocar em evidência quais máquinas ou agenciamentos maquínicos estão em jogo na experimentação de gregarismos e liberdades, e quais subjetividades se "fabricam", respectivamente, por meio de tais agenciamentos no tempo presente.

Por meio do olhar teórico das investigações deleuzo-guattarianas, visouse cartografar os modos pelos quais as formas subjetivas evidenciadas no presente aludem a modos diferentes de se relacionar, ao mesmo tempo em que constroem um meio ambiente. A hipótese de investigação foi a de que os modos de se relacionar com o meio ambiente se diferem conforme os agenciamentos maquínicos que lhes são imanentes.

Nesse sentido, a acepção deleuzo-guattariana tenciona expandir as noções de máquinas empregadas no sentido convencional, em que essas palavras assumem associação com as mecânicas, eletrônicas, informacionais ou ciborgues. Ainda que possam manter eixos etimológicos comuns (téchne, arte), existem as técnicas como instrumentos capazes de alterar o espaço que nos rodeia, e as técnicas capazes de transformar quem somos pelos saberes e práticas que criamos sobre nós mesmos: "As mutações ontológicas são sempre maquínicas [...] o agenciamento maquínico e a máquina técnica, tida como um de seus componentes, são 'produtores de Ser"' (LAZZARATO, 2014, p. 74).

A primeira seção apresenta os conceitos de máquina, agenciamento, desejo e subjetivação, e orientam de que modo tais conceitos aludem a efeitos de acoplamento corpo-máquina. Em seguida, buscam-se delinear os conceitos de máquinas técnicas e máquinas desejantes, buscando demonstrar de que modo foram empregues nesta investigação. Por fim, as seções analíticas buscam demonstrar de que modo os conceitos de tecnologia e máquina podem ser pensados na prática, na perspectiva filosófica deleuzo-guattariana, demonstrando modos pelos quais os agenciamentos corpos-máquinas se relacionam com o meio ambiente na atual conjuntura. A fim de materializar esses conceitos filosóficos no recorte analítico aqui apresentado, selecionaramse as materialidades discursivas cartografadas em sua expressão no âmbito citadino e em sua expressão artística num espaço estratégico. 


\section{Máquina, agenciamento, desejo e subjetivação: um arcabouço conceitual}

A primeira consideração acerca do conceito de máquina é de que este não está empregue em sentido metafórico. As máquinas existem, objetivamente: "[...] o homem² compõe máquina desde que esse caráter seja comunicado por recorrência ao conjunto ${ }^{3}$ de que ele faz parte em condições bem determinadas" (DELEUZE; GUATTARI, 2011, p. 508). Em vez da metáfora, os autores adotaram a hipótese de que cada máquina é uma determinação de elementos por recorrência e comunicação. Trata-se, então, de um phylum maquínico. A máquina tem uma "individualidade" própria 4 , imediatamente pensada em relação ao corpo social, e não em relação a um organismo biológico humano (DELEUZE; GUATTARI, 2011), o que traduz a máquina como uma grande extensão em relação com os fluxos. Deste modo:

Definimos a máquina como qualquer sistema de cortes e fluxos. Assim, tanto falamos de máquina técnica, no sentido usual da palavra, como de máquina social, ou de máquina desejante. É que, para nós, máquina não se opõe de modo algum nem ao homem nem à natureza [...] Por outro lado, máquina não se reduz ao mecanismo (DELEUZE, 2006, p. 280281).

Em outro momento, Deleuze (1992, p. 2016) explica que em cada tipo de sociedade houve uma correspondência a um tipo de máquina: "as máquinas simples ou dinâmicas para as sociedades de soberania, as máquinas energéticas para as de disciplina e as cibernéticas e os computadores para as sociedades de controle". Lazzarato (2019) dá continuidade às associações referidas anteriormente. Este autor entende por máquinas técnicas simples, o plano inclinado e a alavanca, por exemplo. Acerca delas, discute que seu arcaísmo não pode levar à falsa compreensão de limitação de seu poder, uma vez que, citando $O$ mito da máquina, de Mumford, explicita que a máquina

\footnotetext{
2 "[...] nunca é um indivíduo que pensa ou que cria, mas um indivíduo dentro de uma rede de instituições (escolas, teatros, museus, bibliotecas etc.), de tecnologias (livros, redes eletrônicas, computadores etc.), de fontes de financiamento público e privado, imerso e tradições de pensamento e práticas estéticas, engolfado em uma circulação de signos, ideias e obras que o forçam a pensar e criar" (LAZZARATO, 2019).

3 "O conjunto homem-cavalo-arco forma uma máquina guerreira nômade nas condições de estepe. Os homens formam uma máquina de trabalho nas condições burocráticas dos grandes impérios. O soldado de infantaria grego compõe máquina com suas armas nas condições da falange. $O$ dançarino compõe máquina com a pista nas condições perigosas do amor e da morte..." (DELEUZE; GUATTARI, 2011, p. 508).

${ }^{4}$ Lazzarato (2019) concebe essa diferença da seguinte forma: enquanto o século XVIII pode ser pensado à luz do conceito de tecnologia/técnica, dado o grande desenvolvimento de ferramentas e instrumentos que caracterizaram esse contexto, bem como a produção do "indivíduo técnico" da primeira Revolução Industrial; o século XIX pode ser pensado como o século das máquinas, que operaram por meio de um descentramento das funções do ser humano e a destituição do "indivíduo técnico", já que as ferramentas passam a ficar à mercê das máquinas.
} 
arcaica do antigo Egito dos faraós já colocava em funcionamento a exploração do trabalho dos escravos.

Tais autores complementam, ainda, que as máquinas, por si só, não explicam nada, que nem mesmo a máquina técnica trabalha por conta própria. Todas as máquinas são atreladas à máquina social ${ }^{5}$, orientada por vontades que aludem à determinada conformação social que preexiste a uma determinação tecnológica. Derivando das teorizações de Deleuze e Guattari, Berardi (2019, p. 15) compõe que "máquina é o que se concatena. Máquina é a concatenação de entidades (metais, líquidos, conceitos, formas) que funcionam de acordo com uma determinada finalidade".

Levando em conta esses apontamentos teóricos, é sempre preciso analisar os agenciamentos coletivos pelos quais elas (as máquinas) situam-se apenas como parte, pois o que pode ser encontrado no acesso aos instrumentos são multiplicidades que não cessam de ser atualizadas. Desse modo, o presente artigo adota de Deleuze e Guattari (2011; 2012), de Lazzarato (2014; 2019), bem como de Hui (2020), a ideia de que o desenvolvimento dos tipos de máquina anunciadas em cada sociedade é imanente a uma vontade de verdade e, consequentemente, a um modo de vida previamente desejado, de forma que as máquinas preexistem à atualização de seu uso prático e objetivo. As máquinas acoplam-se e desacoplam-se conforme os fluxos orientados pela vontade de verdade e pelo desejo, ambos, imanentes às máquinas sociais.

Indo adiante, agenciamento é o nome dado ao acoplamento corpomáquina ${ }^{6}$, bem como aos efeitos que advém dessa conformação. Um agenciamento não faz parte nem de um domínio social puro, nem do domínio técnico (físico) puro, mas emerge no acoplamento de ambos:

Um elemento técnico continua abstrato, completamente indeterminado, enquanto não o relacionamos a um agenciamento que ele supõe. $\mathrm{O}$ que vem primeiro com relação ao elemento técnico é a máquina: não a máquina técnica, mas a máquina social ou coletiva, o agenciamento maquínico que vai determinar o que é o elemento técnico em tal momento, quais são seus usos, sua extensão, sua compreensão. É por intermédio dos agenciamentos que o phylum seleciona, qualifica e até mesmo inventa os elementos técnicos (DELEUZE; GUATTARI, 2012, p. 81).

\footnotetext{
${ }^{5}$ Levando essa lógica às últimas consequências, Lewis Mumford chegou a afirmar que "[...] a própria sociedade é uma máquina, ou melhor, uma megamáquina. É a sociedade enquanto megamáquina que engendra, organiza e agencia num mesmo movimento os seres humanos e as máquinas técnicas" (LAZZARATO, 2019, p. 107).

6 “Já não há nem homem nem natureza, mas unicamente um processo que os produz um no outro e acopla as máquinas" (DELEUZE; GUATTARI, 2011, p. 12).
}

Revbea, São Paulo, V. 16, № 6: 10-30, 2021.

revista brasileira educação ambiental 
Nessa perspectiva, o agenciamento também é "[...] um campo de possíveis, de virtuais tanto quanto de elementos constituídos [...] se a máquina é aberta, se ela é relação [...] sua individuação não está dada de uma vez por todas, seu funcionamento é adaptável' (LAZZARATO, 2019, p. 140). Além disso, "os agenciamentos são passionais, são composições de desejo. $O$ desejo nada tem a ver com uma determinação natural ou espontânea, só há desejo agenciando, agenciado, maquinado" (DELEUZE; GUATTARI, 2012, p. 83).

Um diálogo entre Deleuze e Parnet captura, de maneira precisa, o que se concebe por desejo nesta analítica: o desejo é o sistema de signos asignificantes com os quais se produz fluxos de inconsciente no campo social. Não há eclosão de desejo, seja qual for o lugar em que aconteça, que não coloque em xeque as estruturas estabelecidas (DELEUZE; PARNET, 1998, p. 64). Para essa perspectiva teórica, o desejo é revolucionário, porque sempre quer mais conexões, mais agenciamentos.

Assim, o desejo está sempre acoplado numa máquina desejante como "combustível". Não há máquina que não seja movida por algum desejo, um sistema que ou funciona pela afirmação da potência de vida, por mecanismos de recusa ao estabelecido ou por um desejo reativo e reacionário. Na primeira via, o desejo como categoria mais ampla, move o social, cria outras instâncias e permite a abertura de universos psicossociais. A máquina é desejante, ao passo que o desejo também é maquinado.

Tudo dependerá se este estiver alinhado a um agenciamento que o permita abrir fluxos em suas potências de criação. Caso contrário, o desejo pode orientar a vias reativas, materializadas em maquinismos entorpecidos, em vez de revolucionários. Com o passar do tempo, tornou-se mais difícil traçar formas de resistências aos maquinismos entorpecidos, uma vez que a máquina externa, bem como a máquina mecânica de metal reluzente, a máquina visível nos espaços, transformaram-se em máquinas invisíveis, "[...] interiorizaram-se, tornaram-se infomáquina, biomáquina, nanomáquina, potência penetrante" (BERARDI, 2019, p. 99).

$\mathrm{Na}$ visão dos autores acionados até aqui, tornou-se imperativo, nas sociedades hodiernas, a criação de agenciamentos maquínicos revolucionários. "Se não se montar uma máquina revolucionária capaz de se fazer cargo do desejo [...], o desejo continuará sendo manipulado pelas forças de opressão e repressão, ameaçando, por dentro, máquinas revolucionárias" (DELEUZE, 1992, p. 90).

Por essas razões, Guattari (2012) dirá que as transformações tecnológicas características do presente são capazes de produzir subjetividades $^{7}-$ e, portanto, mecanismos de sujeição -, isso é, modos de ser

\footnotetext{
7 “[...] o paradigma estético de Guattari convoca a uma estetização do social e do político, mas reivindica a produção de subjetividade como prática e preocupação central de um novo modo de ação e organização política" (LAZZARATO, 2014, p. 19).
}

Revbea, São Paulo, V. 16, № 6: 10-30, 2021. 
e estar no mundo que podem trabalhar tanto para o melhor como para o pior. Chega, inclusive, a conceber que tecnologias como a informática e a tecnociência não são nada mais do que formas hiperdesenvolvidas da própria subjetividade humana, mas uma subjetividade que desejou expurgar-se sob seu domínio tecnicista (GUATTARI, 1993; 2012). Acerca dessa questão, Lazzarato (2014, p. 18) complementa: "é essencial entender que a subjetividade $e$ as subjetivações que o capitalismo produz são feitas para a "máquina". Haja vista que ele transpõe a questão do sujeito para a da subjetivação, sempre moldável dependendo do agenciamento a qual está sujeita, o capitalismo é um sistema eminentemente "maquinocêntrico".

Tais considerações aludem num modo de pensar os maquinismos do mundo presente como orientadores de modos de vida ou modos de existência (GUATTARI, 2009; LAZZARATO, 2019). Nessa perspectiva, os acoplamentos maquínicos abrirão campos de múltiplas interferências entre uma tendência à homogeneização universalizante, que se encarquilha na repetição de clones subjetivos, e uma tendência heterogenética, modo que se refere a um reforço da heterogeneidade e da singularização de seus componentes, que se caracteriza pela afirmação da diferença. Em outras palavras, "[...] modo de existência significa que a máquina não é uma 'unidade absoluta', um 'bloco fechado', uma 'substância', ou seja, uma 'coisa' já individuada, já 'acabada', morta [...]" (LAZZARATO, 2019, p. 139).

Tudo dependerá "[...] de como for a articulação dos modos de existência com os agenciamentos coletivos de enunciação", sendo que "o melhor é a criação, a invenção de novos Universos de referência; e o pior é a massmediatização embrutecedora, à qual são condenados hoje em dia milhares de indivíduos" (GUATTARI, 2012, p. 15-16 grifo meu). Para que aconteça a invenção de novos universos de referência, "[...] a subjetivação política deve necessariamente atravessar esses momentos nos quais as significações dominantes são suspensas e a servidão maquínica é cancelada" (LAZZARATO, 2014, p. 21-22).

Significa dizer que as relações encontradas numa dada sociedade serão efeitos de um agenciamento humano-máquina (BERARDI, 2019; DELEUZE, 1992; DELEUZE, GUATTARI, 2012; GUATTARI, 2012; HUI, 2020; LAZZARATO, 2019). Sendo assim, os autores dão pistas de questões centrais ao tipo de investigação que aqui se delineia: "Dado determinado efeito, qual é a máquina que poderá produzi-lo? E dada uma máquina, para que ela pode servir?" (DELEUZE; GUATTARI, 2011, p. 13). 


\section{As máquinas técnicas e máquinas desejantes}

Apresentados os conceitos na seção anterior, ainda é necessário admitir que não existe máquina em sentido único, uma vez que esta adquire conformações mediadas por fatores já discutidos anteriormente.

Neste artigo, o termo máquina técnica ou gregária foi adotado para se referir a acoplamentos reprodutores de relações sociais reativas. Estas são capazes de (re)produzir a lógica do capital, mas não de criar relações exteriores à mesma. A máquina técnica/gregária se move por meio do desejo que, neste caso, orienta-se numa via reativa. Finalmente, a máquina técnica/gregária não se resume a uma categoria econômica, mas tem forte relação com os aparelhos de Estado e à sua interioridade, tomada como modelo de pensamento de um socius que condiciona sua característica reprodutivista. Nesta discussão, concorda-se que "[...] o Estado é a soberania [...] a soberania só reina sobre aquilo que ela é capaz de interiorizar, de apropriar-se localmente" (DELEUZE; GUATTARI, 2012, p. 24).

O perigo das máquinas técnicas foi ensaiado por Berardi (2019), que afirmara que as tecnologias interconectadas criam sistemas complexos de tipos "vivos-sistêmicos", porque esse acoplamento, ou agenciamento maquínico, acaba por constituir máquinas inteligentes que, quando interconectadas, se comportam como superorganismos. Na conformação de superorganismo, há uma tendência de que as pessoas humanas, incorporadas na relação comunicativa, reproduzam um número crescente de automatismos técnicos, acabando por se comportarem como um sistema automático, reprodutor da lógica do capital, isso é:

A conexão envolve corpos conscientes e sensíveis, mas o corpo consciente e sensível é um meio passivo e não essencial da conexão. A sensibilidade não tem nenhuma função na relação de conexão. $\mathrm{E}$, de fato, tende a se apagar, desativarse, quanto mais disseminada a conexão se torna (BERARDI, 2019, p. 129).

Nessa lógica, os mecanismos sociais acabam sendo despersonalizados, de modo que "[...] decisões que parecem ser humanas são cada vez mais interpretações humanas de decisões automáticas" (BERARDI, 2019, p. 131). O autor também deixa pistas de que estão na sensibilização as táticas de fuga para os automatismos maquínicos que nos capturam em suas redes cuja velocidade é cada vez mais implacável.

Por outro lado, adotou-se a noção de máquinas desejantes para se referir às "[...] categorias fundamentais da economia do desejo [...] não distinguem os agentes das suas próprias peças, nem as relações de produção das suas próprias relações, nem a socialidade da tecnicidade" (DELEUZE; GUATTARI, 2012). "Máquina desejante, por exemplo, é um sistema não- 
orgânico do corpo, e é nesse sentido que falamos de máquina molecular ou de micromáquinas" (DELEUZE, 2006, p. 281). A relação que a máquina de desejante assume com o Estado é, portanto, de exterioridade: "[...] a máquina de guerra (exemplo de máquina desejante) é exterior ao aparelho de Estado" (DELEUZE; GUATTARI, 2012, p. 12 grifo meu), não apenas exterior a ele, mas ela mesma, é uma exterioridade, uma vez que ganha formas para além de suas táticas de captura e funcionamento.

Deve-se ressaltar que "[...] são as mesmas máquinas, sob dois regimes diferentes - embora seja uma estranha aventura para o desejo, desejar repressão" (DELEUZE; GUATTARI, 2011, p. 50), como se sustenta no primeiro caso. Enquanto a máquina técnica do aparelho de Estado se caracteriza pelo sedentarismo; a máquina de guerra desejante se caracteriza pelo nomadismo (DELEUZE; GUATTARI, 2012).

Assim, o poder de destruição e sujeição atribuído às máquinas técnicas é, ao contrário, próprio da máquina do capital, orientado social e politicamente (LAZZARATO, 2019). O motivo dessa atribuição equivocada ${ }^{8}$ é que utopias tecnociber, em vigor nas sociedades ocidentais, encamparam uma dupla promessa, emergida a partir dos anos 1970, nas sociedades do pós-guerra, que via nas máquinas cibernéticas a possibilidade de uma nova subjetividade pós-humana e a liberação da dominação capitalista. Reside nessa dupla promessa a ideia de que "a ruptura viria das máquinas e não da política, das revoluções da técnica e não da organização revolucionária" (LAZZARATO, 2019 , p. 104). Na lógica posta em vigor por meio dessas utopias, a relação estratégica entre máquina técnica e máquina desejante é apagada (LAZZARATO, 2019), o que reflete no apelo tecnicista, característico de nossos tempos.

$\mathrm{Na}$ analítica de Lazzarato (2019) e Hui (2020), até mesmo as possibilidades de mudança orientadas pelas máquinas desejantes, tendem a ser capturadas pela lógica do capital, de modo que a ordem política, garantida por dispositivos econômicos, jurídicos e tecnológicos, é continuamente rompida pelas máquinas de guerra, que praticam essas rupturas, orientando, atualizando e dando consistência aos dispositivos tecnológicos e não o inverso. Em outras palavras, ao evoluir, "[...] a megamáquina substitui os 'humanos' por máquinas técnicas, mas estas nunca poderão substituir a megamáquina social [...] a máquina técnica nunca poderá se autonomizar e dominar a máquina social' (LAZZARATO, 2019, p. 108).

Apresentadas essas considerações, a seção posterior tem o objetivo de discutir de que modos as noções de máquina técnica nos agencia com o meio

\footnotetext{
8 Também por essa atribuição equivocada as variadas formas de interrogação acerca das máquinas técnicas (algoritmos, bitcoin, nanotecnologia, inteligência artificial, plataformas digitais etc.) são mais comuns, em detrimento de questionamentos direcionados à máquina social (capitalista), na verdade a responsável por agenciamentos maquínicos que capitalizam e orientam as relações sociais ao lucro e a exploração (LAZZARATO, 2019).
}

revista brasileira educação ambiental 
ambiente, que tipo de relações e subjetividades produzem, e que desejos utilizam como "combustível" nesses agenciamentos.

\section{Máquina na interface ambiental: as tecnologias de dominação}

Apresentado anteriormente o conceito de máquina técnica, a presente seção busca traçar algumas considerações acerca de suas interfaces com o meio ambiente, visando engendrar que relações produzem essa interface. Após algumas considerações teóricas da mesma interface, um segundo momento apresenta e analisa dois casos que, nesta analítica, buscam dar "concretude" a este agenciamento maquínico.

A progressiva deterioração do meio ambiente, objeto em estudo neste ensaio, é decorrente da intensiva separação entre as modalidades técnicas e os regimes sensíveis que estas agenciam. Imanente a esta separação, o Homo oeconomicus é, ao mesmo tempo, produto e peça chave no componente de uma vontade social para a qual as técnicas de transformação da natureza, somadas às técnicas de dominação e objetivação dos sujeitos, encontram-se submissas às técnicas capazes de refletir sobre quem somos.

Retomando a acepção de Guattari (2012), de que os mecanismos de sujeição maquínicos podem trabalhar tanto para o melhor como para o pior desta vez pensando esses elementos em interface à nossas relações com o meio ambiente - o autor demonstra esse paradoxo presente no advento do domínio técnico, característico das sociedades informacionais (apesar de as mesmas não esgotarem a invenção de Universos):

[...] de um lado, o desenvolvimento contínuo de novos meios técnico-científicos potencialmente capazes de resolver as problemáticas ecológicas dominantes e determinar 0 reequilíbrio das atividades socialmente úteis sobre a superfície do planeta e, de outro, a incapacidade das forças sociais organizadas e das formações subjetivas constituídas de se apropriar desses meios para torná-los operativos (GUATTARI, 2009, p. 12).

nos levaram a formãos subjetivas in condic̃es sociais e desejantes foram essas que, nos guiaram a modos condições sociais e desejantes foram essas que nos guiaram a modos depauperados de reger a vida no abismo que vem caracterizando nossas relações com o meio ambiente?

Admitindo que haja muitas "entradas" possíveis a essa questão, seguem-se algumas pistas na perspectiva dos autores acionados para esse debate. Uma delas, a de que a modernidade nos privou de um regime sensível e ético, no sentido de práticas voltadas a si mesmo, restando a essa figuração recente do ser humano um uso indiscriminado de parafernálias tecnológicas 
geradoras de modos de vida orientados pela semipresença. Tais parafernálias não apenas mediam nossas relações com o mundo, mas nos traduzem modos de enxergá-lo. Está em questão uma noção maquínica produtora de agenciamentos em sentido mais empobrecido.

$\mathrm{Na}$ roupagem verde, o Homo oeconomicus não conhece mais o meio ambiente pela epiderme, pelo cheiro e pelas glândulas, mas pelas mediações das máquinas técnicas que o conectam a um mundo que também já se encontra traduzido neste agenciamento.

Ele calcula a velocidade com que as calotas polares desaparecem. Ele mede o extermínio das formas de vida não humanas. Sobre alterações climáticas, ele não fala a partir da sua experiência sensível - sobre aquele pássaro que já não volta na mesma época do ano, sobre aquele inseto do qual já não se ouvem as estridulações, sobre aquela planta que já não floresce ao mesmo tempo que essa outra. Ele fala com números, com médias, cientificamente. Ele pensa ter dito algo quando estabelece que a temperatura vai subir tantos graus e que a precipitação vai diminuir tantos milímetros. Ele até fala em "biodiversidade". Ele observa a rarefação da vida na terra a partir do espaço. Cheio de orgulho, ele pretende agora, paternalmente, "proteger o ambiente", o qual nunca lhe pediu nada do tipo (INVISÍVEL, 2018, p. 36-37 grifos dos autores).

Deste modo, acerca das máquinas técnicas interiores ao aparelho de Estado, trazem-se para análise dois casos, visando, por meio deles, visibilizar características desse agenciamento maquínico: seu caráter expansionista e imperialista (LAZZARATO, 2019), criador de seu próprio exército colonial (HUI, 2020), agenciado por serviços, transportadores, consumidores etc.

Um caso passível de análise é o do purificador de água portátil da marca LifeStraw $^{9}$ (Figura 1), desenvolvido recentemente pela empresa suíça Vestergaard Frandsen. De acordo com o texto que acompanha sua matéria, a intenção do produto é a de ajudar populações carentes do mundo (sobretudo residentes de vários estados africanos), que não teriam acesso à água potável. O "canudo" pode filtrar de 700 até 1.000 litros de água, o que garante seu uso durante um ano/pessoa. Sua capacidade de filtragem ainda garante a proteção contra contaminações de patógenos recorrentes, como é o caso dos parasitas verme da Guiné, e elimina 99,9999\% de bactérias e vírus, garantindo proteção total contra microrganismos causadores de diarreia, disenteria, tifoide e cólera, além de Salmonela.

\footnotetext{
9 Informações referentes ao LifeStraw podem ser encontradas em:

$<$ https://www.orientista.com.br/produto/2904-purificador-de-agua-portatil-lifestraw>.;

$<$ https://www.bbc.com/portuquese/vert-fut-43646495>. e

$<$ http://ciclovivo.com.br/inovacao/tecnologia/suicos-criam-canudo-que-filtra-agua-contaminada/>.
}

Revbea, São Paulo, V. 16, № 6: 10-30, 2021.

revista brasileira 


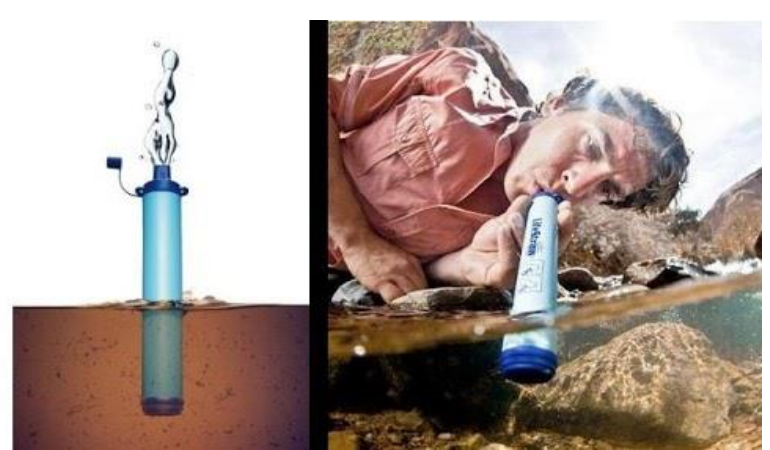

Figura 1: Purificador de água portátil LifeStraw.

Fonte: <https://www.orientista.com.br/produto/2904-purificador-de-agua-portatil-lifestraw>.

É evidente a importância do efeito proporcionado por essa máquina num cenário já depauperado. Contudo, a análise aqui delineada visa colocar em evidência que a invenção, veiculação e uso desse produto - e do acoplamento maquínico que ele enseja - não altera o quadro político-econômico-ecológico culminado para que ela se fizesse necessária. A pobreza extrema, característica de nossos tempos, é imanente às táticas imperialistas capilarizadas por uma geopolítica global, para a qual o lucro é condição desejante.

O outro caso analisado, característico das máquinas técnicas, é o da projeção de vídeo referente ao nascer do sol em telas de LED, projetado na Praça Tiananmen, em Beijing, China, durante o ano de 2014 (Figura 2). A gravação projetada se caracterizava pelo mesmo tempo de duração que o fenômeno natural acontece, não se tratando de uma decisão acionada pelo governo chinês, mas por uma companhia de turismo, dado que, no contexto, a poluição atmosférica impedia que se visse o céu da cidade. O papel do governo chinês acerca desse caso se resumiu à outra projeção, em LED posicionado próximo ao comentado anteriormente, com o seguinte slogan: "Cuidar da atmosfera é dever de todos ${ }^{10 " .}$

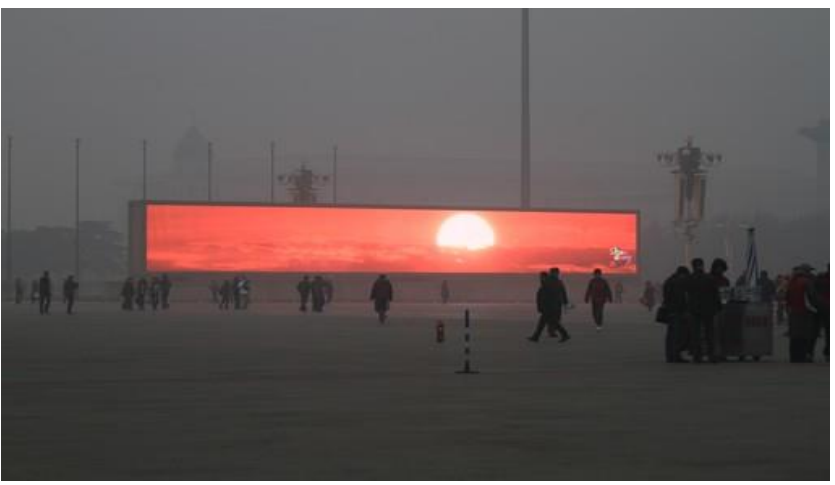

Figura 2: Nascer do sol em telas de Led em Beijing, China.

Fonte: $<$ https://epocanegocios.globo.com/Informacao/Dilemas/noticia/2014/01/tomada-porpoluicao-china-transmite-nascer-do-sol-por-telas-de-led.html>.

Fonte: <https://epocanegocios.globo.com/Informacao/Dilemas/noticia/2014/01/tomada-por-poluicaochina-transmite-nascer-do-sol-por-telas-de-led.html>. 
Novamente, a projeção do vídeo neste caso também se entremeia a um cenário depauperado, desta vez, a qualidade do ar. Apesar do slogan estatal aludir à responsabilidade social, o vídeo projetado pela empresa parece agenciar a um tipo de mensagem promotora do status quo, um comando visual que alude a um "continuem trabalhando", mesmo que as condições ambientais pareçam não favorecer à manutenção da ideia de uma normalidade fabricada por esses aparatos maquínicos.

A faceta da pobreza maquínica presente nesses dois casos é a mesma que dá elementos para pensarmos a nós mesmos como subjetividades agenciadas em mecanismos capilares de colonização e exploração de recursos de algumas nações sobre outras, condição que, como no primeiro caso, leva ao excedente e consequente poluição dos rios e lagos e, também, a superprodução de insumos, o que polui o ar atmosférico, característica do segundo caso.

Haja vista que o Estado não trabalha para impedir os monopólios que consagram esses casos, o funcionamento maquínico imanente a eles não rompe com a lógica do sedentarismo, uma vez que não opera por meio da exterioridade. Vale lembrar, acerca desses casos, que "não foram as máquinas que fizeram o capitalismo, mas o capitalismo, ao contrário, que faz as máquinas" (LAZZARATO, 2019, p. 142). Sabemos que "[...] é no capital que se engancham as máquinas e os agentes, de modo que seu próprio funcionamento é miraculado por ele" (DELEUZE; GUATTARI, 2011, p. 23).

A tendência à homogeneização universalizante e reducionista agenciada pelas máquinas técnicas está imanente à fabricação de subjetividades "escravas" (LAZZARATO, 2019). Estas trabalham para a garantia dos automatismos e de modos de vida embrutecidos pela lógica maquínica das empresas, como ambos os casos aludem. Não apenas não estão inclinadas para a superação ou descentralização da hostilidade do capital, como operam pela vontade de que esse automatismo, pela via da homogeneização embrutecedora, exista. Tudo isso porque a máquina técnica não é autocriadora, ela pensa ser capaz de resolver os problemas, mas não de pôr em discussão sua "existência" (LAZZARATO, 2019).

As subjetividades "escravas" são produtos e efeitos de uma servidão maquínica (LAZZARATO, 2014), uma modalidade de sujeição servil, na qual se atendem vetores que vem "de cima para baixo", geralmente ligados ao Estado, mas também ao mercado, no que tange às formas ecológicas do reger a vida.

[...] a servidão maquínica não se constrange com os dualismos sujeito/objeto, palavras/coisas ou natureza/cultura. $O$ dividual não se opõe às máquinas, nem faz uso de um objeto externo; ele é adjacente às máquinas. Juntos, eles constituem um dispositivo "homens-máquinas" nos quais homens e máquinas são meras partes recorrentes e intercambiáveis de um processo de produção, comunicação, consumo etc. que os excede (LAZZARATO, 2014, p. 29). 
As considerações nesta citação evidenciam a impossibilidade de se identificarem singularidades criativas por meio das máquinas técnicas, uma vez que as possíveis quebras na lógica do agenciamento gregário são amortecidas numa configuração global que elimina o sujeito individuado e a relação entre agentes - da qual resultam a inteligência, os afetos, as sensações, a cognição, a memória -, restando a sujeição maquínica ou, neste caso, servidão maquínica, voltada exclusivamente para a operacionalização técnica do sistema financeiro que opera num agenciamento empresarial. No perspectivismo ameríndio, as máquinas técnicas são agenciamentos tecnológicos que nos põem em conexão a doses de ilusão: "São como um troféu que a ciência e o conhecimento nos deram e que usamos para justificar o rastro que deixamos na Terra" (KRENAK, 2020, p. 59).

Contudo, como expresso na seção dedicada à conceituação de máquinas, essa modalidade de agenciamento não é a única possível, uma vez que o desejo que orienta tais componentes é difuso na estratificação de qualquer sociedade.

Assumindo a mesma lógica analítica, a seção a seguir tem o objetivo de discutir de que modos, desta vez visando as máquinas desejantes, esse agenciamento nos atrela ao meio ambiente, que tipo de relações e subjetividades produzem, e que desejos orientam esses agenciamentos. São as formas atuais de governamento das vidas - e os usos maquínicos decorrentes das máquinas sociais gregárias - que se deve atacar para que outro mundo possível se eleja, ainda que não nos caiba a 'resposta' de que mundo seria esse (STENGERS, 2015).

\section{As Máquinas desejantes de Roberta Carvalho e Eduardo Srur}

Já existe uma base de dados suficiente na pesquisa acadêmica que denota investigações acerca do uso de agenciamentos maquínicos capazes de propor uma "virada ontológica" acerca do uso gregário da tecnologia.

Moser et al. (2020) afirmam que o Padlet pode ser uma ferramenta interativa, capaz de auxiliar investigações interessadas em mapear concepções de ambiente e Educação Ambiental, sendo eficaz na formação crítica de professores. Lima, Santana e Souza (2020), por sua vez, investigaram e demonstraram que a plataforma FlexQuest tem grande relevância nos projetos que viram a conservação dos recursos hídricos. Por fim, vale citar a investigação de Teles (2020), que demonstrou de que modo as tecnologias cisternas domiciliares tem contribuído para melhorar as condições de vida da população nas comunidades rurais. Não é objetivo deste artigo entrar no mérito de cada uma dessas investigações supracitadas, mas apenas demonstrar que pesquisas recentes têm reconhecido possibilidades maquínicas que não se esgotam no uso técnico do determinismo tecnológico.

Neste ínterim, a obra da artista paraense Roberta Carvalho, apresentada e discutida como máquina desejante, é decorrente do projeto Symbiosis e está 
referenciada em um texto que intercala produções escritas e imagéticas. A escolha deste componente se deu pelo modo no qual a artista brasileira coaduna num mesmo agenciamento máquinas desejantes, arte contemporânea e saberes tradicionais.

As expressões artísticas da artista perfilam-se em composições visuais (Figura 3), que ganharam forma nas copas de árvores da ilha Combú, localizada em Belém do Pará (PA). Tais composições adensam seus contornos por meio de feixes de pixels desenhando rostos de membros da população ribeirinha que habitam essa região e navegam de barco da ilha para o continente. De que modo a instalação dessa artista paraense pode ser lida como máquina desejante, ou mesmo máquina de guerra? Que experimentações cotidianas ela é capaz de incitar na produção de subjetividades sensíveis, que fabricam relações em planos que não os da grande máquina capitalista ou de Estado?

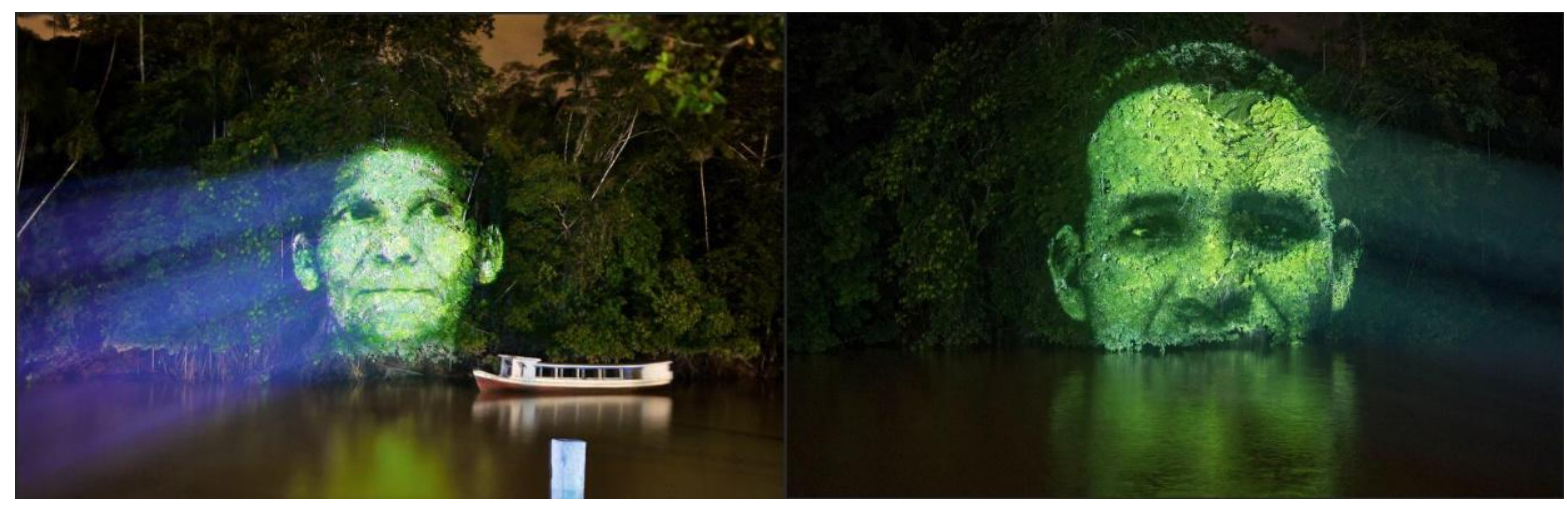

Figura 3: Fotografias de projeções de rostos de membros da população ribeirinha, parte integrante do projeto Symbiosis, da artista visual paraense Roberta Carvalho.

Fonte: $<$ http://artenaescola.org.br/boletim/materia.php?id=77410>.

Num momento histórico em que os agenciamentos da máquina técnica desumanizam as relações por meio de códigos e que "o código tornou-se segunda natureza, e aí circulamos entre signos codificados como se fossem árvores, torres, rostos de pessoas desconhecidas" (BERARDI, 2019, p. 102), a proposição de uma instalação em que a artista "dá rosto" a alguns habitantes da população ribeirinha paraense pode ser lida como sua instauração num tempo-espaço que, talvez, não os reconhecesse como entes que ali habitam.

Uma das potências criadoras de Roberta Carvalho é a de selecionar rostos não contemplados nos vetores hegemônicos dos modos de produção das subjetividades dominantes, daí a noção de instauração fazer sentido na analítica dessa obra. Ao cumprir certos requisitos de estilo, a obra de arte é passível de instauração (ROLNIK, 2002). A própria definição da artista visual ressalta a instauração singular desta obra, especificamente: entre a folhagem marrom e verde, "essas fisionomias evocam questões como memória e identidade dos povos amazônicos e suscitam ainda outro debate interessante: o de que a tecnologia pode aproximar a arte do espaço público" (ESCOLA, 2018, s/p.). 
Como a obra incita a memória, a noção de instauração de Pelbart (2017) se expande: além de sujeitos, faz-se possível instaurar lugares e percursos. Propondo o trajeto de barco numa velocidade reduzida - deslocada de seu uso para o trabalho - a autora cria zonas de lentidão. "A máquina de guerra libera um vetor específico de velocidade" (DELEUZE; GUATTARI, 2012, p. 78), fator que contribui para percepções outras do espaço.

Marcos Reigota e Bárbara do Prado (2008, p. 13) destacam a importância das legitimações e divulgações das práticas sociais e pedagógicas cotidianas de inúmeros anônimos, haja vista que "os narradores/as constroem não só suas subjetividades e especificidades, mas elaboram e interpretam o local e o tempo em que vivem". No caso específico do rosto desses ribeirinhos, instauram-se, sobretudo, entes indissociáveis da paisagem que lhes serve como anteparo, haja vista que se sabe que essa população nativa desempenha um papel fundamental na manutenção da biodiversidade desta localidade. É o que vem sendo tratado pelo conceito de Sociobiodiversidade no âmbito da macropolítica. Em efeitos de sentido, a artista acaba por narrar esse mesmo conceito, só que pelo uso da maquinação artística micropolítica imanente a uma maquinação social macropolítica, uma vez que arrasta uma população minoritária frente à varredura da política brasileira e das luzes maiores de uma maquinaria que os apaga.

O que esses autores clamam, é que a busca por um processo mais democrático de habitar um local e toda a sua complexidade exige que, no interior dos distantes gabinetes, o cidadão citadino elaborador de projetos seja capaz de levar em conta as "leituras de mundo" sobre diversos aspectos que fazem o Brasil contemporâneo, pela observação atenta dos anônimos envolvidos cotidianamente na construção de uma sociedade justa [...]" (REIGOTA; PRADO, 2008, p. 13). Nessa leitura, a arte de Roberta Carvalho é capaz de tensionar esse anonimato.

Ao "rostificar" uma superfície que tende a ser esquecida pela densidade da paisagem, este ato arrasta consigo um feixe de singularidade producente de um movimento ético, que clama pela sensibilização do olhar, a fim de reconhecer práticas realizadas por aqueles que estão nas margens, como as populações ribeirinhas ou extensionistas rurais: "Quanto mais mecanismos de projeção uma ferramenta comporta, mais ela mesma age como arma, potencial ou metafórica" (DELEUZE; GUATTARI, 2012, p. 77). A arma se associa aos revides, que se caracterizam pelo fator inventivo da máquina desejante.

Reigota e Prado (2008) ressaltam que, no adensamento das matas, processos de implementação de sistemas Agroflorestais, como os utilizados pelo manejo de açaizal em São João do Pacuí (MG), estão longe de serem reconhecidos como saberes verdadeiros, dada a hegemonia de práticas centralizadoras provenientes das próprias instituições de ensino, do Partido Verde ou de movimentos como o Greenpeace. 
O que está em questão nessa obra são existências que ganham aderência, seres solicitudinários, possibilitando universos que adquirem um tipo de registro na memória. É, sobretudo, uma aposta ética, pois também "multiplica, ao infinito, as 'embreagens existenciais', acedendo a universos criativos mutantes" (PELBART, 2016, p. 82). A existência - de um povo, uma cultura, uma materialidade - não é da ordem da dicotomia metafísica: existe ou não existe, mas da ordem das intensidades, operando por limiares qualitativos provenientes de certos territórios ou universos que ganharam algum contorno (literalmente). A máquina de guerra, neste caso, se faz ponto de intersecção do corpo orgânico com o corpo inorgânico da máquina eletrônica (BERARDI, 2019, p. 108-109).

Como efeito dessa obra, o que se considera por "rostificação" é menos a figura de um rosto pixelizado nas copas das árvores decorrente de um disparo de canhão de fótons em si, mas sua capacidade imanente de dar forma a protosubjetividades (PELBART, 2016; 2017), levadas em conta pelo Estado desde que no "lugar" mesmo da exterioridade. Como também anunciou Guattari (2012, p. 118): "não existe trabalho algum que incida sobre as formas materiais que não presentifique entidades imateriais".

Ainda que a artista instaure protosubjetividades sem a ambição de uma universalização ou salvacionismo, sua instalação permite uma "varredura" do lugar, mesclando elementos ético-políticos, no sentido de que dão visibilidade (sobretudo de forma política) a entes que pedem passagem: "Em vez de dada de antemão, a existência constitui as próprias balizas dos agenciamentos artísticoexperimentais e político-experimentais" (LAZZARATO, 2014, p. 77).

A noção de agenciamento maquínico que permeia essas composições, por mais que se componha de aparatos mecânicos e elétricos, disparadores de fótons, ao ganhar um tom sensível, se exercita num movimento desejante. Há uma passagem do sensível como um de seus objetivos: "No caso do meu projeto, a natureza é a hospedeira da arte. A árvore não é apenas um anteparo para um vídeo ou uma imagem, mas se constrói também como obra", e complementa: "Quis que as pessoas refletissem sobre a relação entre identidade e natureza e também entre arte e tecnologia" (ESCOLA, 2018, s/p).

Dando continuidade à analítica das máquinas identificadas em sua potência criadora, concebem-se, também, as obras de Eduardo Srur. O artista paulistano se tornou referência na cidade e no país porque realiza intervenções no espaço urbano, cuja potência é de mobilizar o espectador. A escolha pela análise de algumas de suas obras ${ }^{11}$ residiu em sua capacidade estética de promover incômodos com relação ao modo de existência anestesiado - pois alguns processos que caracterizam a cinza espacialidade da urbe tornaram-se tão comuns, que nossos mecanismos ópticos permitem-nos transitar por eles naturalizando o que poderia não ser naturalizado - por meio do qual transeuntes percorrem espaços citadinos.

11 Disponíveis em: <https://www.hometeka.com.br/f5/7-intervencoes-urbanas-do-artista-brasileiro-eduardo-srur/>; $<$ http://www.eduardosrur.com.br/intervencoes/pets > e <http://www.eduardosrur.com.br/intervencoes/caiaques $>$.

revista brasileira educação ambiental 
O aperfeiçoamento das propostas do artista o levou a focar sua produção num tripé erigido por questões éticas, ambientais e arquitetônicas, o moveu a um agenciamento singular que caracteriza a obra Caiaques (Figura 4). Como o artista declara numa entrevista, sua obra mantém o potencial de afectação democrático (CANTON, 2009). Nela, cento e cinquenta esculturas compostas por caiaques de plástico e remos de alumínio, manequins de plástico, roupas de tactel, parafusos e cabos de aço são lançados a certa altura do rio Pinheiros, localizado na cidade de São Paulo. Não se detendo ao caráter de fixidez exigido em PETS, os caiaques boiam e transitam conforme o devir das águas. Um efeito estético curioso está demonstrado na segunda figura, em que as esculturas se aglomeram numa "ilha" de lixo superficial, acentuando contornos que muito remetem ao mapa do Brasil, um efeito não planejado pelo autor da obra.

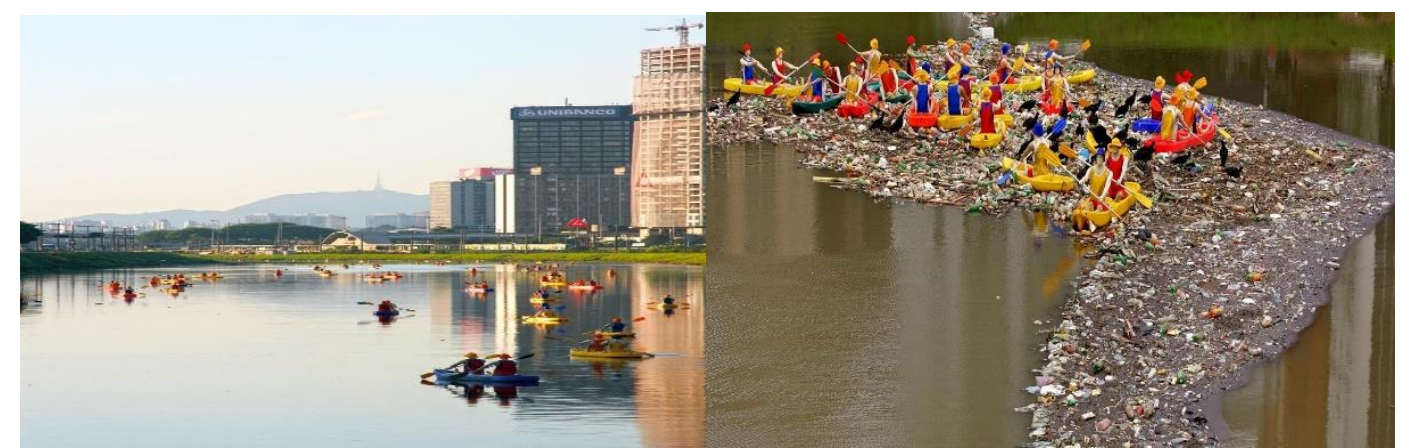

Figura 4: Fotografias de instalações referentes à obra Caiaques, do artista plástico paulistano Eduardo Srur. Fonte: $<$ http://www.eduardosrur.com.br/intervencoes/caiaques $>$.

A escolha de Srur pela paisagem urbana encontra eco em Guattari (2012), que discute sobre o ethos estabelecido com os espaços urbanos. De acordo com esse autor, os cientistas já nos prediziam que, nos decênios que vivemos, cerca de $80 \%$ da população mundial viveria em aglomerados urbanos e que, mesmo os $20 \%$ restantes desta estatística, seriam tributários ao habitat da cidade por meio de liames técnicos e de civilização. A preocupação, ao contextualizar esses dados, estaria no esmaecimento da distinção entre a cidade e a natureza, o que teria o efeito perverso da segunda subsistir em pequenos territórios "naturais", em meio a grande paisagem de concreto. Além disso, os grandes centros urbanos, como a região de São Paulo, acabam por dificultar singularidades individuais e coletivas, uma vez que foram simplificadas a espacialidades meramente facilitadoras do trânsito e do deslocamento das forças do Estado na produção de vidas sedentárias.

Em Caiaques, especificamente, ele declara que considerou "[...] a ideia de fazer esse resgate histórico do que era o rio, do que ele representava para a cidade e do que ele é hoje. Quando colocamos caiaques com manequins, há um caráter de provocação, estamos falando de uma coisa séria, mas há uma ironia" (CANTON, 2009, p. 58). A instalação dos 100 caiaques e dos 150 manequins, que começava na ponte das Bandeiras e ia até a ponte Eusébio 
Matoso, também remeteu à ideia de "[...] fazer uma obra onde falta o ser humano, falta a consciência de preservação, de cuidado com o meio ambiente. Todas as minhas obras cada vez mais pensam numa mensagem direta para 0 espectador" (CANTON, 2009, p. 58-59).

Caiaques são "borrões" na estética da espacialidade da urbe. A própria instalação é uma poluição visual, mas no sentido incômodo que essas obras são capazes de causar aos nossos aparatos perceptivos. Romero (2018, p. 134) completa que, sob diversos nomes, - intervenção urbana, arte participativa, colaborativa ou relacional - "a arte pode assumir um papel fundamental em relação à abertura de corpos e mentes a inéditas formas de se viver em contexto urbano".

Na perspectiva analítica das máquinas estéticas, a heterogeneidade dos componentes que o mundo acena - linguísticos, corporais, espaciais engendra, também, uma heterogênese ontológica. O "consumo" de certas obras é imanente à possibilidade de alargamento de pontos de vista, pois todo descentramento estético dos pontos de vista, toda multiplicação polifônica dos componentes de expressão passam pelo pré-requisito de uma "[...] desconstrução das estruturas e dos códigos em vigor e por um banho cósmico nas matérias de sensação, tornando possível uma recomposição, uma recriação, um enriquecimento do mundo, [...] uma proliferação não apenas das formas, mas das modalidades de ser (GUATTARI, 2012, p. 105). Na perspectiva guattariana, as máquinas estéticas "nos propõem modelos relativamente mais bem realizados desses blocos de sensações suscetíveis de extrair um sentido pleno a partir das sinaléticas vazias que nos investem por todos os lados"; complementa, ainda, que são "nas trincheiras da arte que se encontram os núcleos de resistência dos mais consequentes ao rolo compressor da subjetividade capitalística" (GUATTARI, 2012, p. 105).

Os agenciamentos maquínicos presentes nas obras de Carvalho e Srur ensejam outros modos de vida que não aqueles ligados ao sedentarismo e gregarismo, imanentes à produtividade do capital. Elas propõem máquinas desejantes que também são estéticas (GUATTARI, 2012). Estas são capazes de desterritorializar aquilo que se naturaliza nos aparatos ópticos e de engendrar subjetividades tão mutantes quanto à processualidade maquínica que incita sua paisagem.

Nessas vias, em vez dos automatismos que mantém a normalidade de um capital que fagocita o ambiente, as obras de Carvalho e Srur aludem à tendência heterogenética, modo pelo qual se refere a um reforço da heterogeneidade e da singularização de seus componentes. " $A$ arte também é uma máquina, um agenciamento dos termos - o artista e a obra" (LAZZARATO, 2014, p. 73). Tratam-se menos de topologias que repousam sobre pontos ou objetos, mas sobre hecceidades (DELEUZE; GUATTARI, 2012). 
As grandes mudanças políticas, ou seja, as rupturas, são sempre da máquina social e da máquina de guerra, nunca das máquinas técnicas. São os poderes da máquina de guerra revolucionária, das rupturas subjetivas e coletivas e dos processos de conversão da subjetividade que decorrem delas que precisamos problematizar (LAZZARATO, 2019. p. 130).

Enquanto as máquinas técnicas funcionam com base na condição de não estarem desarranjadas; as máquinas desejantes (categoria mais ampla da máquina de guerra) não param de se desarranjar enquanto funcionam. Ambas as instalações rearranjam os fluxos da estética normalizante, daí sua potência revolucionária: "O problema da máquina de guerra é o dos revezamentos, mesmo com meios parcos, e não o problema arquitetônico do modelo ou do monumento. Um povo ambulante de revezadores, em lugar de uma cidade modelo" (DELEUZE; GUATTARI, 2012, p. 50).

$A$ arte utiliza frequentemente essa propriedade, criando verdadeiros fantasmas de grupo que curto-circuitam a produção social com uma produção desejante, e introduzem uma função de desarranjo na reprodução de máquinas técnicas (DELEUZE; GUATTARI, 2012, p. 49 grifo meu).

As maquinações de Carvalho e Srur acionam percepções de que "[...] homem e natureza não são como dois termos postos um em face do outro [...] mas são uma só e mesma realidade essencial do produtor e do produto (DELEUZE; GUATTARI, 2011, p. 15)". A axiomática subjacente nessas expressões artísticas não pode simplesmente ser entendida como um uso outro do instrumental técnico; a mudança, como não poderia deixar de ser, reside na própria máquina social, que, nestes casos, "[...] substitui as antigas codificações, e organiza todos os fluxos descodificados, inclusive os fluxos de código científico e técnico" (DELEUZE; GUATTARI, 2011, p. 310). De repente (mas não por acaso):

...] um processo se desencadeia secretando outros sistemas de referência ali onde o mundo se achava fechado. Como em toda criação (não importa se artística, científica ou social), a suspensão do curso habitual das coisas afeta antes de tudo a subjetividade e suas formas de expressão ao criar as condições para uma nova subjetivação (LAZZARATO, 2014, p.22-23). 


\section{Conclusões}

Com a analítica do referencial teórico adotado, buscou-se demonstrar que a compreensão das relações que estabelecemos com o meio ambiente é mediada, necessariamente, pelos agenciamentos maquínicos compostos pelo acoplamento corpo-máquina. Disso decorre que as formas de vida, atuais e futuras, estão/estarão subjacentes ao desejo que orienta a máquina social. Ao se direcionar críticas aos modos de vida não ecológicos, é ao arranjo da máquina social que se faz preciso atacar e, consequentemente, à produção dos desejos gregários canalizados pela mass mídia mas, também, pelo Estado e mercado.

Fabular maquinações que operem na antípoda dos modos de vida orientados pela semipresença, caracterizados pela privação de regimes sensíveis e éticos, implicará na lembrança do agenciamento como campo de possibilidades. Para que emerjam universos de referência não orientados pelos gregarismos, será necessário não submeter a capacidade de invenção e criação ao domínio técnico, de modo que isso bastasse na orientação dos modos de vida. A crítica ambientalista que coaduna criação de agenciamentos que caracterizem máquinas revolucionárias será tarefa das sociedades porvir.

\section{Referências}

BERARDI, F. Depois do futuro. São Paulo: Ubu Editora, 2019.

DELEUZE, G. Conversações. São Paulo, ed. 34, 1992.

DELEUZE, G. A ilha deserta: e outros textos. São Paulo: lluminuras, 2006.

DELEUZE, G.; GUATTARI, F. O anti-Édipo: capitalismo e esquizofrenia 1. São Paulo: Editora 34, 2011.

DELEUZE, G.; GUATTARI, F. Mil platôs: capitalismo e esquizofrenia 2. vol. 5. São Paulo: Editora 34, 2012.

DELEUZE, G.; PARNET, C. Diálogos. São Paulo: Editora Escuta, 1998.

GUATTARI, F. Da produção de subjetividade. In: PARENTE, A. (org.). Imagem-máquina: a era das tecnologias do virtual. Rio de Janeiro: Editora 34, 1993.

GUATTARI, F. As três ecologias. Campinas, São Paulo: Papirus, 2009.

GUATTARI, F. Caosmose: um novo paradigma estético. São Paulo: Editora 34, 2012.

HUI, Y. Tecnodiversidade. São Paulo: Ubu Editora, 2020.

INVISÍVEL, Comitê. Aos nossos amigos: crise e insurreição. 2. ed. São Paulo: $\mathrm{n}-1$ edições, 2018.

LAZZARATO, M. Signos, Máquinas, Subjetividades. São Paulo: Edições Sesc São Paulo: N-1 edições, 2014. 
LAZZARATO, M. Fascismo ou revolução? O neoliberalismo em chave estratégica. São Paulo: N-1 edições, 2019.

LIMA, V.H.M.; SANTANA, O.A.; SOUZA, T.E.M.S. Plataforma Flexquest: um recurso educacional voltado para a conservação dos recursos hídricos. Revista Brasileira De Educação Ambiental, v.15, n.5, 2020, p.47-59.

MOSER, A.S.; GREGÓRIO, A.; PIRES, E.A.C.; MOREIRA, A.L.O.R. (2020). Concepções de ambiente e Educação Ambiental de professores: o padlet como uma ferramenta interativa. Revista Brasileira De Educação Ambiental, V.15, n.5, 2020, p. 20-36.

STENGERS, I. No tempo das catástrofes: resistir à barbárie que se aproxima. São Paulo: Cosac Naify, 2015.

TELES, R. Tecnologias Sociais para a convivência com o semiárido: uso de cisternas domiciliares em comunidades rurais do Ceara. Revista Brasileira De Educação Ambiental, V.15, n.5, 2020, p.320-332. 